\title{
Analysis of Patients Undergoing Prostate Biopsy Procedure In Outpatient Care
}

Patrícia Mitsue Saruhashi Shimabukuro ( $\nabla$ mitsue_s@hotmail.com )

Federal University of São Paulo

Carla Morales Guerra

Hospital Sancta Maggiore

RICHARLISSON BORGES DE MORAIS

Federal University of Uberlândia

Monica Taminato

Federal University of São Paulo

\section{Research Article}

Keywords: Infection control, Biopsy, Prostate, Quality of health care, Nursing

Posted Date: September 1st, 2021

DOl: https://doi.org/10.21203/rs.3.rs-806478/v1

License: (c) (i) This work is licensed under a Creative Commons Attribution 4.0 International License. Read Full License 


\section{Abstract}

Currently in the concept of de-hospitalization and consequently an increase in invasive procedures performed in the extra-hospital environment. This work aims to identify the signs and symptoms of an adverse event related to prostate biopsy. This is a cohort and retrospective research through the registration of patient care in electronic medical records after the exam. In the period from 2016 to 2018, 3,570 exams were performed, with 491 patients presenting the criteria for the classification of infection related to the procedure that strictly obeys the criteria established by the Centers Diseases Control (CDC). The inclusion criteria for patients were those who, within 15 days after performing the prostate biopsy, had emergency care due to the presence of signs and symptoms. The exams analyzed were urine culture and blood culture collected at the time of emergency care. The results were that of the 491 patients evaluated, 38 (9\%) patients required hospitalization, the average age of the hospitalized patients was 71.5 years and all had at least one associated comorbidity on positive cultures, 13 for E. coli with total sensitivity to aminoglycosides and carbapenems and partial sensitivity to fluoroquinolones, 1 Protein spp sensitive to aminoglycosides and carbapenems and 1 Salmonella spp sensitive to fluoroquinolones and carbapenems. Thus, it is noted the importance of the infection control nurse's activity in the diagnostic medicine units for the elaboration of protocols adapted to the outpatient reality.

\section{Background}

In the current scenario, invasive procedures are being performed in the extra-hospital environment, allowing de-hospitalization, and increasing complexity in the diagnostic medicine scenario. For this, infection prevention and transmission practices help provide patient safety. According to Ordinance No. $2616 / 98$ of the Ministry of Health, infection related to healthcare (IRAS) is defined as any infection acquired in the healthcare environment or after performing diagnostic or therapeutic procedures performed during the hospitalization period ${ }^{1-3}$.

The elderly population has been increasing over the years and chronic diseases end up appearing. For there to be a model of primary care for this population, preventive and efficient action by the diagnostic and therapeutic medicine sector is important, favoring the early detection of diseases and thus improving the quality of life $e^{4}$.

Among the diseases that we should evaluate in the elderly are cancer (lung, pancreas, mouth, thyroid, breast, prostate, intestine, gastric), arterial and peripheral disease, and lung diseases ${ }^{5-6}$.

It is estimated that in developed countries at least $25 \%$ of patients undergoing hospitalization end up acquiring some infection. According to the World Health Organization (WHO), 5-10\% of patients end up acquiring some type of infection related to health care ${ }^{4-5}$.

The test that helps to carry out the early detection of prostate cancer is the biopsy performed guided by ultrasound, which consists of a safe examination that can be performed in an outpatient setting, and the 
removed fragments will be sent for analysis to the laboratory of pathological medicine. With this result, it is possible to determine the best therapy to be adopted for the patient ${ }^{6-13}$.

In this scenario, the role of an infection control professional in a diagnostic medicine unit is justified for monitoring patients after this exam is performed, accompanying the possibility of complications, the need for hospitalization and the evaluation of the institutional protocol adopted.

The risk of acquiring infection in out-of-hospital services is usually low, but there are studies that demonstrate the occurrence and dynamics of the transmission of microorganisms, although data are scarce. The lack of this data ends up creating a difficulty in diagnosing infections related to health care due to the patient's short stay and also due to the difficulty in differentiating infections acquired in the community.

\section{Objective}

- Present the signs and symptoms related to the infection in prostate biopsy.

- To evaluate the most prevalent microorganisms, antibiotic prophylaxis, sensitivity profile and bacterial resistance of patients undergoing the prostate biopsy procedure.

\section{Methods}

\section{Ethical aspects}

This project was approved by the Research Ethics Committee of Unifesp 02/02/2020 under the number 3.818.112. In this study, the participants' total confidentiality and anonymity was guaranteed, as established in Resolution No. 466/2012.

\section{Study design, location, study period}

This is a cohort and retrospective study to assess the prevalence of infectious symptoms related to the prostate biopsy procedure performed in the extra-hospital environment from 2016 to 2018, correlating the tests performed (blood culture and urine culture) and the sensitivity profile and resistance to antimicrobials.

The institutional protocol for antimicrobial prophylaxis used during the study period was ciprofloxacin orally $500 \mathrm{mg}$ one hour before the exam and extending for another 3 days after the exam. In case of signs of seriousness, the patient and his family are advised to appear for immediate assistance in the emergency room.

\section{Inclusion criteria}


This study included all patients who presented signs and symptoms of infection as described in the National Healthcare Safety Network (NHSN) prepared by the Centers Disease Control (CDC), from January 2016 to December 2018, who sought emergency care. This verification was carried out by searching electronic medical records, the tests analyzed were urine culture and blood culture.

\section{Exclusion criteria}

Patients who underwent the procedure in a hospital environment or did not show any infectious signs during the study period were excluded from the study.

\section{Statistical analysis}

A descriptive analysis of patients was used in this study, considering variables such as age, race, clinical, laboratory and treatment-related parameters.

The association between multiresistant bacteria and categorical variables will be tested with the chisquare or Fisher's exact test and the association between continuous variables and the type of multiresistant bacteria being. It is done using Student's or Mann-Whitney's "t" tests, as appropriate.

\section{Results}

The period studied was from January 2016 to December 2018, 3,570 prostate biopsy tests were performed and the total number of patients who presented criteria for infection according to the Centers Diseases Control (CDC) after the examination was 419 (11, 7\%). Of the 491 patients who had infection criteria after the examination, 38 (9\%) patients needed hospitalization.

If we compare the group of patients who had hospitalization and those who did not have hospitalization, we have the following results:

Table 1: Mann Whitney test to compare the group of hospitalized and non-hospitalized for age.

\begin{tabular}{|llll|}
\hline & Average & $\begin{array}{l}\text { Standard } \\
\text { deviation }\end{array}$ & P-valor \\
\hline Age of hospitalized persons & 71,578 & 7,845 & $\begin{array}{l}\text { 0,265(Test of Mann } \\
\text { Whitney) }\end{array}$ \\
\hline Age of people who did not need hospitalization & 69,976 & 6,943 & \\
\hline Number of comorbidities of hospitalized person & 1,842 & 0,973 & $\begin{array}{l}0,244(\text { Test of Mann } \\
\text { Whitney) }\end{array}$ \\
\hline $\begin{array}{l}\text { Number of comorbidities of people who did not } \\
\text { need hospitalization }\end{array}$ & 1,640 & 0,945 & \\
\hline
\end{tabular}

The average age of patients who required hospitalization was 71.5 years and those who did not require hospitalization was 69.9 years and all had at least one comorbidity regardless of whether or not they 
needed hospitalization.

For the variables ages and comorbidities, the Mann Whitney statistical test was used because the event related to the patient's hospitalization is more serious in the clinical aspect and is directly related to the prostate biopsy exam.

Table 2: Chi-square test to verify the possible association between being hospitalized or not in relation to race.

Number of

hospitalized
Quantity that did not require hospitalization
P-valor

0,857

(Exact test de Fisher)

White Race $\quad 30$

296

14

Black Race

2

3

43

In the studied period, a total of 176 exams were collected, of which $142(80.6 \%)$ were urine culture and 35 (19.4\%) were blood culture. Of the exams collected, we had $82(46.5 \%)$ positive exam results, 64 (78\%) of which were urocultures and 18 (22\%) blood cultures considering hospitalized and non-hospitalized patients.

Table 3: Chi-square test to verify the performance of tests due to whether or not you need to be hospitalized.

\begin{tabular}{|lccc|}
\hline & $\begin{array}{c}\text { Number of } \\
\text { hospitalized }\end{array}$ & $\begin{array}{c}\text { Quantity that did not require } \\
\text { hospitalization }\end{array}$ & P-valor \\
\hline $\begin{array}{l}\text { Blood culture not } \\
\text { performed }\end{array}$ & 18 & 365 & $<0,001$ (Exact test \\
\hline $\begin{array}{l}\text { Negative blood } \\
\text { culture }\end{array}$ & 10 & 10 & Fisher) \\
\hline $\begin{array}{l}\text { Positive blood culture } \\
\begin{array}{l}\text { Uroculture not } \\
\text { performed }\end{array}\end{array}$ & 10 & 6 & $<0,001$ (chi-square \\
\hline $\begin{array}{l}\text { Negative urine } \\
\text { culture }\end{array}$ & 16 & 261 & \\
\hline Positive urine culture & 6 & 63 & \\
\hline
\end{tabular}


The chi-square test showed the importance of performing the blood culture and / or urine culture test to identify the microbiological agent to direct the appropriate antibiotic therapy, even considering the prophylaxis performed previously.

Regarding isolated microbial agents considering hospitalized and non-hospitalized patients, 74 (90.2\%) E. coli, 6 (7.3\%) Proteus spp, 1 (1.25\%) Salmonella spp, 1 (1.25\%) Klebsiella spp.

The table below shows the isolated agents and the sensitivity profile.

Table 4: Total of isolated agents in blood culture and urine culture of inpatients.

\begin{tabular}{|lllc|}
\hline & $\begin{array}{l}\text { Blood (absolute number and } \\
\text { percentage) }\end{array}$ & $\begin{array}{l}\text { Urine (absolute number and } \\
\text { percentage) }\end{array}$ & Total \\
\hline E. coli & $7(53,8 \%)$ & $6(46,2 \%)$ & 13 \\
\hline Proteus spp & $1(100 \%)$ & 0 & 1 \\
\hline $\begin{array}{l}\text { Salmonella } \\
\text { spp }\end{array}$ & $1(100 \%)$ & 0 & 1 \\
\hline
\end{tabular}

Regarding the sensitivity profile, we noticed that in E. coli 13 (100\%) were found for aminoglycosides, 13 (100\%) for carbapenems, for cephalosporins 4 (69.3\%) and for fluoroquinolones only 3 (15.4\%). Proteus spp found sensitivity to aminoglycosides and carbapenems only. And in Salmonella spp, sensitivity to fluoroquinolones and carbapenems was found.

\section{Discussion}

Based on the results obtained, it is noted that only 38 patients had hospitalization due to signs and symptoms that could develop into sepsis, the average age was 71.5 years and at least they had a comorbidity that increased the risk factor for an infection. All patients underwent prophylaxis according to the institutional protocol ${ }^{11-12}$.

Even using microbial prophylaxis, cases of complications can happen, and one of them is acute bacterial prostatitis. The main symptoms: perineal pain, fever, chills, urinary urgency, polluria and dysuria. In more severe cases, prostatic abscess and sepsis may occur, in which case hospitalization is recommended for patient follow-up6,14. Other symptoms such as rectal and / or urinary bleeding ( $2.2 \%$ of the cases), hematuria (up to $14.5 \%$ of the cases) and hematopermy (6.5-74.4\% of the cases) disappear within 2 weeks after the exam ${ }^{7-8}$.

Studies corroborate the results of this study and refer us to the importance of antimicrobial rationalization through the performance of uroculture in symptomatic patients for effective and cultureguided treatment (blood culture and / or urine culture) to assess the microbial agent that causes the infection4,5. It is not recommended to prolong the use of prophylactic antibiotics to avoid microbial 
resistance. Thus, it is noted that the institutional protocol is a guide that guides the medical team for the safe performance of the procedure ${ }^{19-20}$.

To target antimicrobial prophylaxis, it is necessary to use antibiotics that have a spectrum for bacteria of the cutaneous flora, rectum and genitourinary tract. E.coli and Streptococcus faecalis are the main etiological agents of prostate biopsy infections, but the local microbiota and the microbial resistance of the region should be considered ${ }^{14-15}$.

In this study, we observed the prevalence of E. coli as an isolated agent in urine culture and blood culture in these patients with total sensitivity to aminoglycosides and carbapenems, reduced sensitivity to cephalosporins and fluoroquinolones as observed in the studies ${ }^{13,14,15,16,20}$.

ANVISA reports that the prevention of multidrug-resistant agents is extremely important, given that the isolated microorganism affects not only the affected site, but also changes the patient's clinical conditions17. In this scenario, it is recommended to implement the antimicrobial management program, which includes the adoption of prophylactic measures to avoid complications in certain procedures, whether in the hospital or out-of-hospital ${ }^{18}$.

Aiming at the quality and safety of the patient, the infection control professional can make periodic visits, with evaluation of procedures, provided with a specific check list and process audit of the units. It is highly recommended to prepare a procedure visit report listing the main items evaluated with the necessary suggestions for adequacy, in view of specific legislation. An action plan is requested, when applicable. Regarding periodicity, it may be appropriate according to the complexity of the procedure and indicators that help to monitor the evaluated procedure ${ }^{1}$.

This study has limitations in relation to the sample, as they are retrospective data but with defined criteria for the collection of these data, which provided a reliable analysis of the data.

In view of the above, it is noted the importance of instrumentalizing the infection control professional who performs out-of-hospital care, performing the combination of biosafety, patient safety and legislation in force and applicable to each situation of the procedures performed in the outpatient setting.

Regarding the prostate biopsy procedure, it is observed the importance of the antimicrobial prophylaxis protocol and the orientation to the patient and his companion about the warning signs for possible complications after the exam.

\section{Conclusions}

In the studies found, it is noted the importance of carrying out an antibiotic prophylaxis protocol for the prostate biopsy procedure, based on the microbiological agents found in the cultures performed (urine or blood). 
This study demonstrated a good result of prophylaxis with ciprofloxacin, however the prophylaxis time is a determining factor to avoid microbial resistance.

We reinforce the importance of the infection control professional for monitoring patients after the examination and classification for infection after the procedure.

\section{Abbreviations}

ANVISA - National Health Surveillance Agency

CDC - Centers Diseases Control

IRAS - Infection Related to Healthcare

NHSN - National Healthcare Safety Network

WHO - World Health Organization

\section{Declarations}

\section{Ethics approval and consent to participate}

We declare for all due purposes, that approval process was registered on the Brazil platform, which is currently in force in the country. This study was approved by the Ethics of the Federal University of Sao Paulo $\mathrm{n}^{\circ} 18222619.9 .0000 .5505$ and Committee and the Ethics Committee co-participant center Senior Prevent Institute through $n^{\circ} 18222619.9 .3002 .8114$.

The authors

\section{Consent for publication}

1 [Name] give my consent for information about myself/my relative (circle as appropriate) to be published in Analysis of patients undergoing prostate biopsy procedure in outpatient care [BMC Infectious Diseases].

I understand that the information will be published without my/my relative's (circle as appropriate) name attached, but that full anonymity cannot be guaranteed.

I understand that the text and any pictures or videos published in the article will be freely available on the internet and may be seen by the general public. The pictures, videos and text may also appear on other websites or in print, may be translated into other languages or used for commercial purposes.

I have been offered the opportunity to read the manuscript.

Signing this consent form does not remove my rights to privacy. 
Name.

Date.

Signed.

Author name.

Date.

Signed.

\section{Availability of data and material}

Not Applicable

Competing interests

The authors declare that they have no competing interests

\section{Funding}

We declare that this study was carried out without funding or other financial resources.

\section{Authors' contributions}

PMSS - literature review, article writing and data collection

CMG - study authorization and review of collected data

RBM - literature review, article review

MT - supervisor of the master's course, review of the article text

We declare that we have read this article in its entirety and agree to its publication in this prestigious journal.

Graciously

\section{Acknowledgements}

The diagnostic medicine team that provided the opportunity to carry out the study.

\section{References}

1. Associação Paulista de Estudos em Controle de Infecção Relacionada a Assistência à Saúde $(\mathrm{APECIH})$. Prevenção e controle de infecções relacionadas à assistência médica extra-hospitalar: 
ambulatórios, serviços diagnósticos, assistência domiciliar e serviços de longa permanência. São Paulo. 2019.

2. Ministério da Saúde. Critérios diagnósticos de infecção relacionada à assistência à saúde. Brasília. 2017.

3. Padoveze MC, Figueiredo RM. O papel da atenção primária na prevenção de infecções relacionadas à assistência à saúde. Rev Esc Enferm USP. 48(6):1137-44.2017.

4. Baba $\mathrm{K}$ e cols. Assessment of antimicrobiral prophylaxis in trasperineal prostate biopsy: a singlecenter retrospective study of 485 cases. J Infect Chemother. 24: 637-640.2018.

5. Chung HS e cols. Prevalence of fluoroquinolone-resistant rectal flora in patients undergoing transrectal ultrasound-guided prostate needle biopsy: a prospective multicenter study. International Journal of Urology. 25(3): 278-283. 2017.

6. Cussans A e cols. The role of targeted prophylactic antimicrobial therapy before transrectal ultrasonography-guided prostate biopsy in reducing infection rates: a systematic review. BJUI. 117:725-731.2016.

7. Danielsen $L$ e cols. Infection after transrectal utlrasonic guided prostate biopsies - a restrospective study. Scantinavian Journal of Urology. 53:2-3, 97-101. 2019.

8. Farag $\mathrm{M}$ e cols Comparing infective complications from transrectal ultrasound guided prostate biopsy following transition to single dose oral ciprofloxacin prophylaxis. Investig Clin Urol. 60:5460.2019.

9. Liss MA e cols. Comparative effectiveness of targeted vs empirical antibiotic prophylaxis to prevent sepsis from transrectal prostate biopsy: a restrospective analysis. J Urol. 194(2):397-402.2015.

10. Papagiannopoulos $\mathrm{D}$ e cols. Predictors of infectious complications after targeted prophylaxis for prostate needle biopsy. J Urol.199(1):155-160.2018.

11. Samarinas $\mathrm{M}$ e cols. A single dose of meropenem is superior to ciprofloxacin in preventing infections after transrectal ultrasound-guided prostate biopsies in the era of quinolone resistance. World $\mathrm{J}$ Urol. 34(11):1555-1559.2016.

12. Womble PR e cols. A statewide intervention to reduce hospitalizations after prostate biopsy. J. Urol. 194(2):403-9.2015.

13. Li CH e cols. Cost-effectiveness of culture-guided antimicrobial prophylaxis for the prevention of infections after prostate biopsy. International Journal of Infectious Diseases. 43:7-12. 2016.

14. Loeb $S$ e cols. Infectious complications and hospital admissions after prostate biopsy in a European randomized trial. Eur Urol.61(6): 1110-4.2012.

15. Roberts MJ e cols. Prostate biopsy related infection: a systematic review of risk factors, prevention strategies and management approaches. Urology. 104:11-21.2017.

16. Toner $L$ e cols.Prevention of sepsis prior to prostate biopsy. Investig Clin Urol. 57(2):94-99.2016.

17. Agência Nacional de Vigilância Sanitária (ANVISA). Prevenção de infecções por microorganismos multirresistentes em serviços de saúde. Brasília. 2021. 
18. Shimabukuro PMS, Guerra CM, Taminato M. Profilaxia e infecções relacionada à biópsia de próstata ambulatorial: Revisão Sistemática. J. Infect. Control, 9(3):188-195.2020. 